This item was submitted to Loughborough's Research Repository by the author.

Items in Figshare are protected by copyright, with all rights reserved, unless otherwise indicated.

\title{
The dimensions of graphic design and its spheres of influence
}

\section{PLEASE CITE THE PUBLISHED VERSION}

http://dx.doi.org/10.1162/DESI_a_00054

\section{PUBLISHER}

(c) Massachusetts Institute of Technology Press (MIT Press)

\section{VERSION}

VoR (Version of Record)

\section{LICENCE}

CC BY-NC-ND 4.0

\section{REPOSITORY RECORD}

Harland, Robert G.. 2019. "The Dimensions of Graphic Design and Its Spheres of Influence". figshare. https://hdl.handle.net/2134/9398. 
This item was submitted to Loughborough's Institutional Repository (https://dspace.lboro.ac.uk/) by the author and is made available under the following Creative Commons Licence conditions.

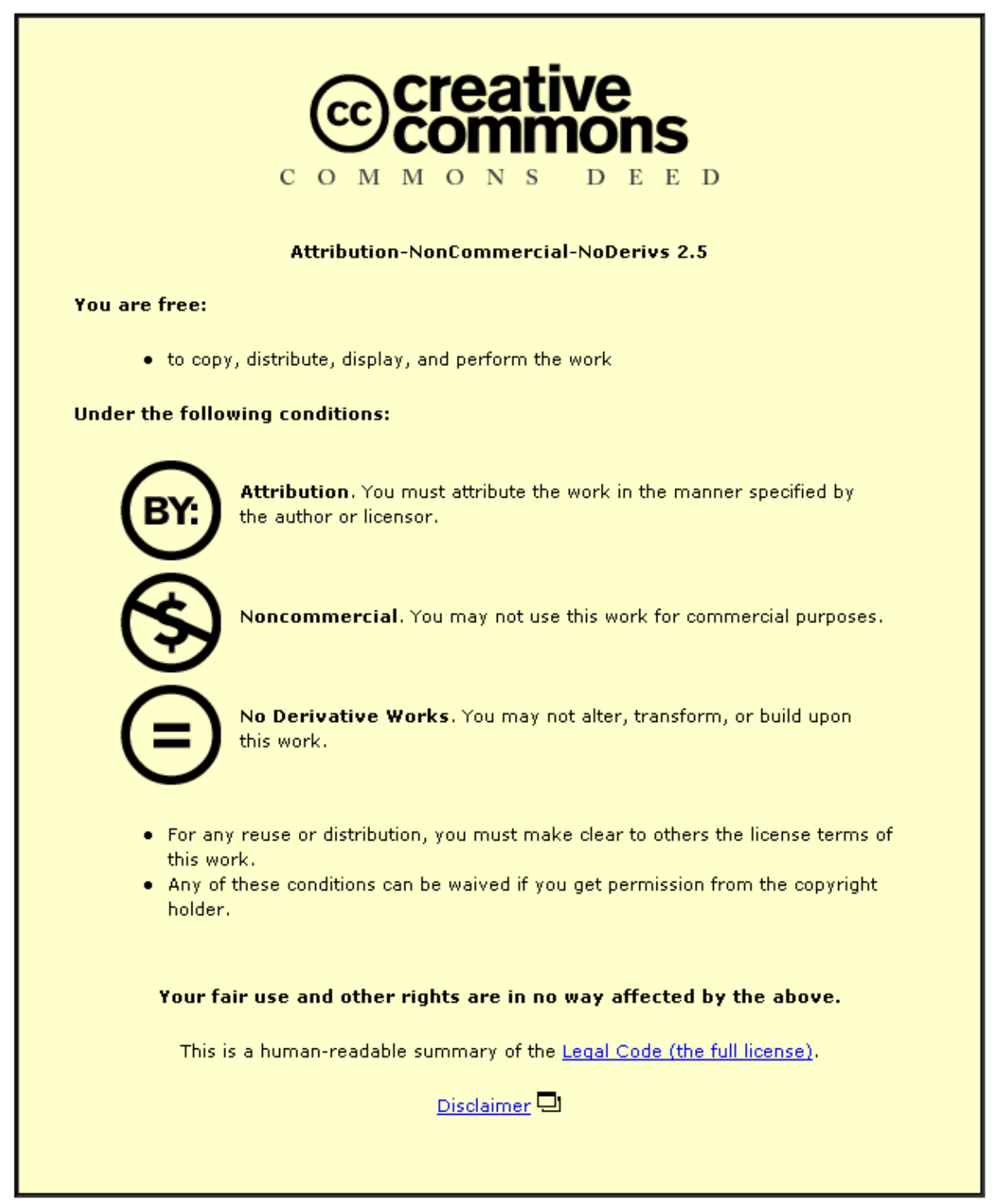

For the full text of this licence, please go to: http://creativecommons.org/licenses/by-nc-nd/2.5/ 


\section{The Dimensions of Graphic Design and Its Spheres of Influence Robert Harland}

1 First discussed formally by the author of this paper in the conference paper, "Redefining the plural domains of graphic design and orientating the subject towards a model that links practice, education, and research." International Association of Societies of Design Research 2007: Emerging Trends in Design Research, November 12-15, The Hong Kong Polytechnic University.

2 Outlined in a presentation, " $O n$ the road to find out" at Finding the question to the answer: a graphic design research symposium, Nottingham Trent University, September 13, 2006

3 Lang, J. Urban Design: A Typology of Procedures and Products. (0xford: Architectural Press 2005), 394.
This paper further expands on the concern about how we depict graphic design to explain its relationships (both "internal" and "external") for the purposes of education, research, and practice. The initial development of this concern led to the identification of what has been described as the critical dimensions of graphic design, and this inquiry has required the analysis and proposed redefinition of the subject's plural domains. The attempt to depict these critical dimensions, or domains, benefitted from a diagrammatic modeling exercise, discussed formally in $2007^{1}$ after having first been outlined a year earlier. ${ }^{2}$ This exercise demonstrated how the traditional definitions, from which the subject emerged and with which it became identified in the first half of the twentieth century, could be represented in diagrammatic form, creating a contemporary interpretation of the subject. The present author has used the visual method of diagrams as a form of rational inquiry to illustrate the shift from traditional to contemporary ways of thinking about the graphic design (Figure 1). The traditional interpretation of graphic design in diagrammatic form by this author, seen on the left, owes much to the way urban design is shown, by Jon Lang in 2005, to have emerged from the overlap between architecture, landscape architecture, city planning and civil engineering. ${ }^{3}$ Whereas the contemporary model seen on the right evolved from numerous attempts by this present author since 2001 to use diagrams as an effective tool for teaching graphic design to students within and without the subject.
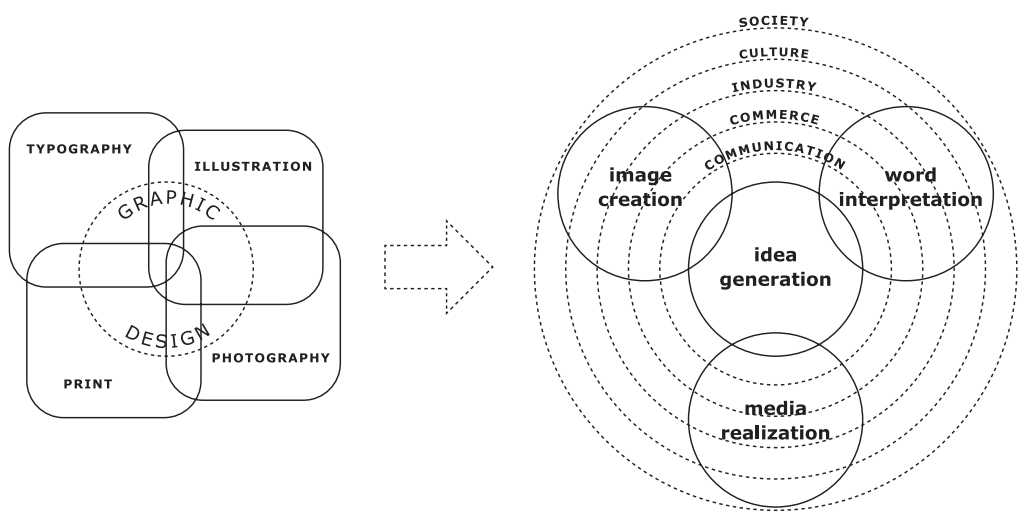

(C) 2010 Massachusetts Institute of Technology 
From the diagram on the left in Figure 1, we can see the roots of graphic design in four very distinct but related activities: typography, illustration, photography, and print. Each of these activities has its own independent and interdependent history. This interpretation of graphic design, and the traditional definitions drawn from it, remained intact until the early $1990 \mathrm{~s}^{4}$; but since then, a wider appreciation of the subject's real potential as a profession, field, and discipline has been constrained by it. Consequently, we have seen further proliferation of and numerous alternative descriptions for what is essentially the same process of design. These new descriptions often align themselves with new technologies (e.g., the Web) or new marketing initiatives (e.g., the proliferation of the term "branding"). Not surprisingly, graphic design's light appears to have dimmmed during this period as more specialized subjects such as illustration, and other closely related disciplines such as information design, asserted their independence. Such assertions have resulted in some confusion in the graphic design "discipline," and in the wider contexts within which graphic design functions.

To explore the relationships in graphic design, and to demonstrate the critical dimensions of the subject without relying on traditional descriptors, a new diagrammatic model was introduced by the author in 2007 that uses a different set of terms drawn from graphic design writing and other nondesign disciplines. These terms focus less on the previously described disciplines from which graphic design emerged, and more on how graphic designers think and act, as interwoven with their many different contexts. In this sense, graphic design has been depicted as a unified thinking and doing activity that involves idea generation, image creation, word interpretation, and media realization, for industry, commerce, culture, and society. Communication, with its theories, models, methods, and practices, is also recognised as central to the process of making meaningful representation.

This model was generated as an attempt to create a basic theoretical model for use in an educational context in the United Kingdom. It placed the generation of ideas at the heart of graphic design thinking and practice, thus aligning with philosophical debate from Plato to Kant. It also argued that the traditional domains of typography, illustration, photography, and print, while contributing significantly to graphic design, are inadequate terms for describing what graphic design is, and what graphic designers do. This configuration shows how the concentric circles, representing the contextual domains, orbit the ideas domain, and yet, through the communication domain, are coded before being expressed as word and image, through media. Or, using the words of Stuart Hall, "codes which govern the relationships of translation between" the shared "conceptual maps" and "language systems" of a culture. ${ }^{5}$

In this paper I critically examine this contemporary model and consider its usefulness from an historical perspective. Note that, in 
6 Steven Heller, The Beginning of History, in Graphic Design History, by Steven Heller and Georgette Balance. (New York: Allworth Press, 2001), ix.

7 Andrew Marr in A History of Modern Britain. (London: Macmillan, 2007), xxii.

8 Flusser, V. (1999). 'About the Word Design' in 'The shape of things: a philosophy of design'. (London: Reaktion Books 1999).

9 A Danziger Syllabus in Graphic Design History, by Steven Heller and Georgette Balance. (New York: Allworth Press, 2001), 333

10 In Bierut, M., Helfland J., Heller S., Poyner, R. (eds.), Looking closer 3: classic writings on graphic design. (New York: Allworth Press. 252) the study of graphic design history, we have been told that historians have their "preferences" and "prejudices" in their interpretation of history, ${ }^{6}$ and that history in general is, "either a moral argument with lessons for the here-and-now or it is merely an accumulation of pointless facts." 7 This paper is equally guilty of preferences and prejudices-those of someone who for two decades was concerned with the "making" process in graphic design. This process amounted to the doing and the thinking, or regarding the latter, what has been described in the Platonic sense as a "theoretically distorted" process of idea generation. ${ }^{8}$ It is written from the perspective of a practitioner-turned-educator, whose desire is to further identify core beliefs and activities of graphic design at a time when technological change and political influence too often conspire to bring about the demise of graphic design, rather than enhance its reputation as a force for good.

If there is any truth in the notion that "no practitioner is a good historian" and that the historian's work "often has little relevance for the practitioner," ${ }^{\prime \prime}$ the intent of this paper is theorybuilding based on a challenge of recent historic perspectives that place graphic design as a declining twentieth-century phenomenon in parallel with print media. The issue emerges auspiciously in recent conferences that take the name of graphic design in the United States and the United Kingdom, as designers call for a new subject name that "truly" reflects the graphic designer's changing role. This expanded role is reflected in the significant increase of undergraduate programs in closely related subject areas, many of which are grounded in graphic design's thinking about curriculum. Few are yet to emerge as models that demonstrate significantly different approaches to the subject, and many agitators for change fail to recognize that graphic design as an integrated process concerned primarily with relationships is not changing — but its context most certainly is. Victor Papanek ${ }^{10}$ criticized this in 1975 as a "relabeling" process; and one might still ask: Beyond the cleverly articulated program validation documentation, what is the difference between graphic design, graphic communication, graphic communication design, and the rest!?! This criticism is vivid and stimulates the belief that there is still much to be known about graphic design as process, as well as product.

This paper considers the usefulness of theoretical modeling in graphic design and seeks to build a closer relationship between the work of educators, researchers, theorists, historians, critics, and practitioners (or crafts people) in a shared territory that is facilitated by the metaphor of a diagrammatic model. It is predominantly a practitioner's response to a perceived need for this form of diagrammatic representation; it is offered as an aid to identifying the future development of graphic design in an academic context-one that is more integrated with practice, if that integration is desirable. 
11 Jessica Helfland and William Drentell, What's so Graphic About Graphic Design? March 10-11, 2007. Pasadena. Reviewed in Eye Magazine, No 64, Vol. 16, Summer 2007.

12 Sharon Poggenpohl, Praima Chayutsahakij, and Chujit Jeamsinkul, Language definition and its role in developing a design discourse. Design Studies, Volume 25, Issue 6, November 2004), 579-605

13 Alan and Isabella Livingston, Dictionary of Graphic Design and Designers. (London: Thames and Hudson Ltd., 1992): 90. (This definition remained intact in the second edition issued in 2003.)

14 Brown, V. A., Harris, J. A., and Russell, J. Y. (Eds.). (2010). Tackling wicked problems through the transdisciplinary imagination. London: Earthscan Ltd. 5.
History has played a part in formulating such a model, consistent with Jessica Helfland and William Drentell's view that "mapping the future of the profession will be difficult without looking back at our history to get a better idea of where we are going." "11 This paper looks ahead by acknowledging the past. Language use plays a critical role. For example, the use of the term "print" in basic definitions of the subject, as will be seen, is an element of the graphic design making process that is practical; but in content and context, print is arguably much less important than, for example, choice of typeface. In fact collaborative discussion about content and communication context more often ignores the technical aspects of production.

\section{The Importance of Language}

One might ask: Should there be a concern about how language is used to describe what graphic design is? Perhaps there should be if that language limits an understanding about how far a subject can be appreciated and developed.

Dictionaries play an important role in determining the use and understanding of language. Attempts to "stabilize language" in the form of dictionaries have been a preoccupation for 4,000 years, and more recently, "specialized dictionaries" have become a common reference tool in modern life, trying to "make clear the terms and definitions for special subdivisions of knowledge." ${ }^{12}$ Since the early 1990s graphic design has been recognized as its own special subdivision of knowledge with its Dictionary of Graphic Design and Designers. Although a second edition appeared in 2003, it retains a traditional, and arguably outdated, definition for graphic design: "Generic term for the activity of combining typography, illustration, photography and printing for the purposes of persuasion, information or instruction. ${ }^{\prime 13}$ This definition is a reasonable attempt to capture the multidisciplinary aspect of the subject and its origin, and it forms the basis for the image shown on the left side in Figure 1. But it is limited when compared to the language used in discussion about graphic design today, (and since the 1980s), for what might be increasingly recognized as a "transdisciplinary" ${ }^{14}$ subject, given its tendency for "personal," "local," "strategic" and "specialized" outcomes.

However, it is ironic that at the point when educators in graphic design felt confident enough to establish a specialized dictionary in the early 1990s - working to clarify terms and definitions for this special subdomain of knowledge - the 'making' activity associated with graphic design was undergoing massive transformation as the advent of new technologies suddenly removed barriers of entry for many potential practitioners. During this period, and since, language to describe graphic design has been unstable, and this lack of stability in itself demands attention if the subject is to develop. Language to describe graphic design therefore must be a contemporary concern, and it needs the urgent attention of those concerned with graphic design. 
15 David Crystal, The Cambridge Encyclopedia of Language. (Cambridge University Press, 1987). 10-13.

16 Shaun Cole focuses on the collaborative nature of the subject with a focus on working practices; his approach moves beyond traditional subject coverage, is more inclusive than usual, and emphasizes teamwork. Dialogue: Relationships in Graphic Design. (London: V\&A Publications, 2005).
As a lexicon, language is a method and system of communication, often adopted and adapted by distinct communities in spoken and written forms. More specifically, the function of language is intricate. The Cambridge Encyclopaedia of Language tells us that its primary function is the communication of ideas, and in this sense it is "referential," "propositional," or "ideational." But it also functions as emotional expression, social interaction, rhythm and control, and accountability; it is instrumental and an expression of identity. ${ }^{15}$ In fact, at times, the communication of ideas is the least important factor, and language frequently functions as emotional expression. For example, swear words or words of amazement do not describe how to fix a leaking tap. In addition to its regulatory function, it has a social function - the simple "hello" or a discussion of the weather. In such cases, language is a form of maintenance; Malinowski, cited by David Crystal in The Cambridge Encyclopaedia of Language describes it as having a "phatic" function, or being simply social and signifying, rather than serving as specific communication.

The basic modeling process shown on the right side of Figure 1 tried to focus attention on more appropriate use of language to describe graphic design, and on its historical influences and how they might be reinterpreted through a new use of language derived from subject discourse. This language is integrated with diagrammatic explanations that help to explain the key relationships. The newer model challenged traditional views of the subject and proposed a unified process of idea generation, word interpretation, image creation, and media realization for social, cultural, industrial, and commercial contexts. This diagrammatic representation is a starting point for developing future descriptions of the subject that are not determined and defined by contributing factors but that establish a foundation for a trans-disciplinary rather than multi-disciplinary dialogue.

\section{From Basic to Applied Research}

The initial attempt to depict graphic design in diagrammatic form grew out of a desire to identify core beliefs and general principles. Its initial purpose was as a visual teaching aid to help students in higher education identify what shaped their learning in the subject. Higher education in the United Kingdom therefore provides the context for this exercise. In this sense it is best described as a "basic research" modeling exercise that demonstrates, to some extent, the collaborative relationships and processes that are known to exist within the subject of graphic design. ${ }^{16}$

This paper reports on an attempt by the author to develop this "basic research" modeling exercise by examining its potential to represent relationships between a wider range of actors, functions, ideologies, and contexts. In this sense the paper moves beyond the use of typography, illustration, photography, print, word interpretation, 
17 George Lakoff and Mark Johnson, Metaphors we live by. (Chicago: The University of Chicago Press 1980).

18 David Potter and Philip Sarre, Dimensions of Society, (London: Hodder and Stroughton, 1974), 3.

19 These "basic," "applied," and "clinical" descriptors are taken from Ken Friedman's paper, "Theory construction in design research: criteria, approaches, and methods." (Design Studies, Vol 24, No 6, November 2003), 510-511.

20 J. Elkins, The Domain of Images. (New York: Cornell University Press 1999), 87.

21 These examples are discussed in Harland, R.G. (2009). "The Dimensions of Graphic Design: in Theory." Paper presented at the International Association of Societies of Design Research: Design: Rigour, and Relevance, Coex, Seoul, Korea, October 18-22, 2009

22 K. van der Waarde, (2009). On Graphic Design: Listening to the Reader. Avans Hogeschool Research Group Visual Rhetoric AKV I St. Joost. 25. image creation, idea generation, and media realization. To make this move, the idea of metaphor is used to help frame the complexity that arises once descriptions and explanations become more specialized and more remote from the traditional definition offered by Livingstone and Livingstone in the early 1990s. In their book, Metaphors We Live, George Lakoff and Mark Johnson argue that metaphor dominates our conceptual system for what humans think, experience, and do. ${ }^{17}$ With this ubiquity in mind, this discussion borrows a metaphor used by Potter and Sarre to explain the dimensions of society as a continent with a number of countries, each of which has "its own history, way of life, dialect, institutions, literature, and ideology."18 This idea can be applied to the origin of graphic design (as well as other subjects, fields, and disciplines that have grown from the need for a holistic approach—urban design being one of them). Graphic design emerged from core territories, parts of which are populated by separatists, some countries are claimed by more than one group, and other regions are yet to be explored. If graphic design is a social activity, with relationships at its heart, then this metaphor is appropriate and the question emerges: What might a graphic design nation look like? This inquiry is concerned specifically with the interests, motivations, preoccupations, and intentions of such a population. In this sense, it attempts to move from a state of basic research to applied research, toward a "clinical research" tool for "micro level research."19 This approach uses diagrams as a visual method for rational inquiry. James Elkins describes the idea of using diagrams in this way as a "diagrammatic fantasy" that is also a "rational inquiry, because we might learn as much by what the diagrams suggest as by applying pictorial and linguistic evidence." "Thinking about images means being led into certain thoughts by images." ${ }^{\prime 20}$

Thinking about the potential application of the diagrammatic models shown in Figure 1 has revealed weaknesses in their scope and diversity as tools for thinking about graphic design beyond a basic level. For example, neither the traditional nor the contemporary diagram incorporate the idea of design in graphic design as a significant domain, while the "graphic" aspect is implicit in typography and illustration (as in the Greek "graphikos"), in photography and printing (as in lithography). What's more, graphic designers generally have not used their own skills (or "tools of their trade") as creators of many diagrams to explain what they do, or what their subject is, in diagrammatic form. The exceptions appear to be Katherine McCoy (1990) and Bruce Brown (1979) ${ }^{21}$ and more recently Karel van der Waarde (who emulates the concentric circles as context configuration seen here in the contemporary model in figure 1). ${ }^{22}$ Historical perspectives about graphic design, from Hollis (2001), Meggs (2006), Jubert (2006), Heller and Balance (2001), and Eskilson (2007), to name a few, do not venture beyond the products of graphic design as visual data. 
23 M. Bierut, W. Drenttel, S. Heller, D.K. Holland, eds. Looking Closer 2: Critical Writings on Graphic Design. (New York: Allworth Press, 1997).

24 Audrey Bennett, Design Studies: Theory and Research in Graphic Design. (New York: Princeton Architectural Press, 2006), 14.

25 Geoffry Fried and Douglas Scott state that "For some time now, the landscape and boundaries of graphic design have been shifting." The Common Core, ed. Steven Heller, The Education of a Graphic Designer. (New York: Allworth Press, 1998), 171.

26 0. Newark, What Is Graphic Design? (Switzerland: Rotovision SA, 2002). ISBN 2-88046-539-7.0xford Illustrated Encyclopedia. Vol 5. The Arts. Oxford University Press.

27 Jack Breen, "Designerly Enquiry," in Ways to Study and Research Urban, Architecture and Technical Design, T.M De Jong and D.J.M van der Voort, ed. (Delft, DUP Science, 2005), 97.

28 This draws from Nigel Cross's discussion about the culture of science, humanities, and design. N. Cross, Designerly ways of knowing. (London: Springer-Verlag, 2006), 2.

Figure 2

The In-Between Realm of Design.

\section{Toward a Model for Education About Graphic Design}

An attempt to model the dimensions of graphic design in visual form might be considered foolish, despite the visual skills associated with the discipline. Heller points out that "various models have been adapted from academia and journalism ... this includes commentaries, manifestoes, reviews, editorials, and reportage," and they usually are derived from the "-isms, -ologies, and -otics" with which these realms are associated. ${ }^{23} \mathrm{Few}$ of the models are said to be discerning. With this critique in mind, the author embarked on this current exercise with a degree of skepticism.

Aside from the work of historians, explaining graphic design through "graphic design" appears to involve the production by graphic designers of self-promotional items, or their writing and designing of books. There is little evidence of the use of diagrams in recent critical writing about the subject, although as some green shoots of research and theory have emerged in the subject, we are beginning to see diagrams used to accompany text explanations about design process and research methods. ${ }^{24}$ And if we return to the earlier use of continent as a metaphor, talk of boundaries and landscapes is not uncommon in graphic design writing. ${ }^{25}$ There is even a feeling of pointlessness about analyzing graphic design too much, when Newark comments that "dividing up graphic design into categories is essentially a fruitless exercise ... 'design' is a portmanteau term: It covers a number of interlaced activities that do not fall into distinct categories." ${ }^{26}$

In contrast to this view, those interested in design studies, rather than graphic design, try to explain design using both diagrams and textual matter. In Figure 2, Breen ${ }^{27}$ suggests that design is the "in-between" realm that bridges the sciences (knowledge) and the arts (expression), and this location does not detract from design's having its own core values. Design is thought by some to be a "third way," with certain aspects of its activity incorporating artistic as well as scientific thinking. Considering this view from the perspective of graphic design, those practitioners with artistic inclinations will place a high value on "subjectivity, imagination, commitment, and a concern for "justice," whereas those motivated by the acquisition of "knowledge" (or a more scientific approach) will seek out "objectivity, rationality, neutrality, and a concern for the

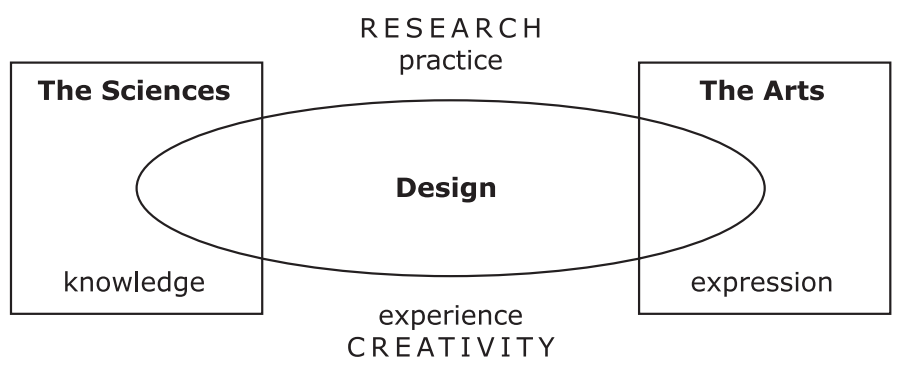

Design Issues: Volume 27, Number 1 Winter 2011 
Figure 3

The Urban Design: “Context, Substantive

Dimensions, and Implementation"

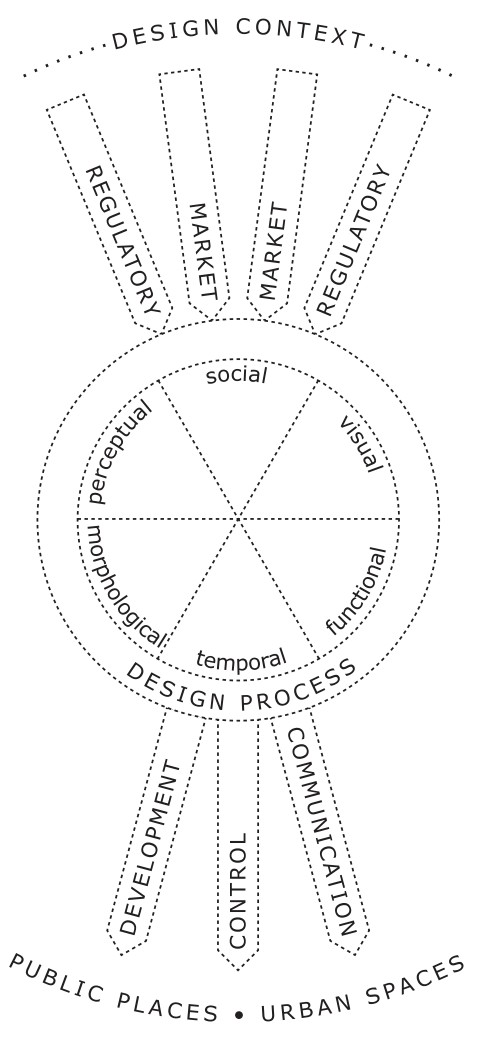

29 Nathan Crilly, Alan F. Blackwell, and P. John Clarkson, "Graphic Elicitation: Using Diagrams as Interview Stimuli." Qualitative Research. Vol. 6(3) 341-366. (London: SAGE Publications, 2006).

30 Mathew Carmona, Tim Heath, Tanner Oc, and Steve Tiesdell. Public Places - Urban Spaces: the Dimensions of Urban Design. (Oxford: Architectural Press, 2003), vi.

31 D. Waugh, Geography: an Integrated Approach ( $3^{\text {rd }}$ ed.). (Thomas Nelson and Sons Ltd. 1995), 507.

32 Denis McQuail and Sven Windahl, Communication Models for the Study of Mass Communication. (England: Longman Group UK Limited, 1981), 2-3. 'truth.'”28 Consequently, graphic designers with an interest in music might wish to design for the music industry, or the cultural sector in general, where self-expression and the needs of the "artist" might be better understood, appreciated, and tolerated. Similarly, an interest in more "scientific" approaches to graphic design might lead a graphic designer toward information design, or a systems approach to their work, such as designing corporate identity.

Diagrams appear to be valuable tools, and they are used for eliciting responses..$^{29}$ Other design fields use diagrams to accompany explanations about the dimensions of their subject. For example, the urban design is partially explained with the use of a diagram to depict contexts, dimensions, and implementation..$^{30}$ An example of this perspective is shown in Figure 3 (redrawn for the purpose of this paper).

In acknowledgement of the views expressed by Glaser about segmentation, and contrary to the skepticism of Heller regarding the various attempts to theorize, or model, the subject of graphic design, the question arises: How might the critical dimensions of graphic design be modeled in diagrammatic form? What might such a "scientific" model look like to the graphic design and non-graphic design communities? These questions are worth pondering.

Many academic disciplines are familiar with the use of diagrammatic models, considering them essential to the thinking and teaching of the subject. Waugh states that models "form theoretical frameworks which may be difficult to observe in the real world, but against which reality can be tested," and in the 1960s Deutsch apparently identified three main advantages to the use of models in the social sciences. ${ }^{31} \mathrm{He}$ argued that models have an "organizing function"; make complicated or ambiguous information clear so that "it can guide the student or research to key points of a process or system"; and help to formulate hypotheses in research and "predict outcomes." Models may be "structural" (diagrammatic) and "functional" (relational). ${ }^{32}$ This paper is concerned with the latter type.

\section{Speculating About the Future of Graphic Design}

This discussion about the use of diagrammatic models thus far has focused on evaluating the past as an impetus for embracing a future that links practice, education, and research. This particular work began in the early part of the millennium, but now there is a wider acceptance of the need to take a step backward before taking two steps forward. In 2007 Helfland and Drentell were reported to suggest that "mapping the future of the profession will be difficult without looking back at our history to get a better idea of where we are going, ${ }^{\prime 33}$ indicating there is clearly a mood for reflection before future projection. 
The intention of including the initial basic contemporary model shown in Figure 1 was to present the idea that there are four key "practical" domains and four key contextual domains that are mediated through the domain of communication. This schema presents the notion that idea generation ${ }^{34}$ (or "ideation") occupies a central place in graphic design and played a significant role in establishing the subject's credibility in the twentieth century. From this central point, the contextual domains, with the social domain at the outer limits, give the visual impression that commerce, industry, culture, and society cover the domains of media realization, word interpretation, and image creation. This "transmission" has a "ripple" and "reverse ripple" effect, pushing out as well as drawing in, influencing as well as being influenced by, these "practical" domains. The model also demonstrates that the domains of idea generation, image creation, word interpretation, and media realization are linked to each other through the idea domain. These areas were initially thought of as domains, and the visual appearance suggested boundary lines. This technique is a common one used in modeling, the intricacies of which will not be explored here. This diagrammatic approach, as a visual method, worked well for the purpose of creating a basic research model, but it is limiting in scope because of the suggestion that these domains are fixed surface areas, equal in size, and it is limiting as a device for interpreting complexity. For example, how might this approach incorporate the ideas about design and its relationship to science and humanities?

A return to the metaphor about graphic design as a continent, or nation, is useful to reconsider at this point. An approach to the use of diagrams found in geography helps reconfigure the idea of overlapping circles used in the initial basic model, as dimensions and contexts. More specifically, the diagramming technique used by Walter Christaller to explain "central place theory" —one of a number of theories for measuring settlement patterns and the "spacing and function" of settlements-offers a useful approach. His primary concern was the distribution and location of settlements, and their "sphere of influence" over inhabitants in the surrounding area. He used the term "central place" for each settlement and depicted them using circles to show the boundary, or sphere of influence, of the central places..$^{35}$

The diagram in Figure 4 explains the development of Christaller's theory, the stages of which are usually shown as a series of separate images. Reading from left to right, it illustrates how Christaller identified boundaries of trade areas and the resulting spheres of influence. These overlap to identify areas served by more than one central place, overcoming areas that were unserved by any central place when circles simply "touch" rather than overlap. Overlap areas are shaded grey. In these overlap areas, first-order settlements are identified (e.g., as villages). These settlements are located as hexagonal trading areas are established, and then areas 


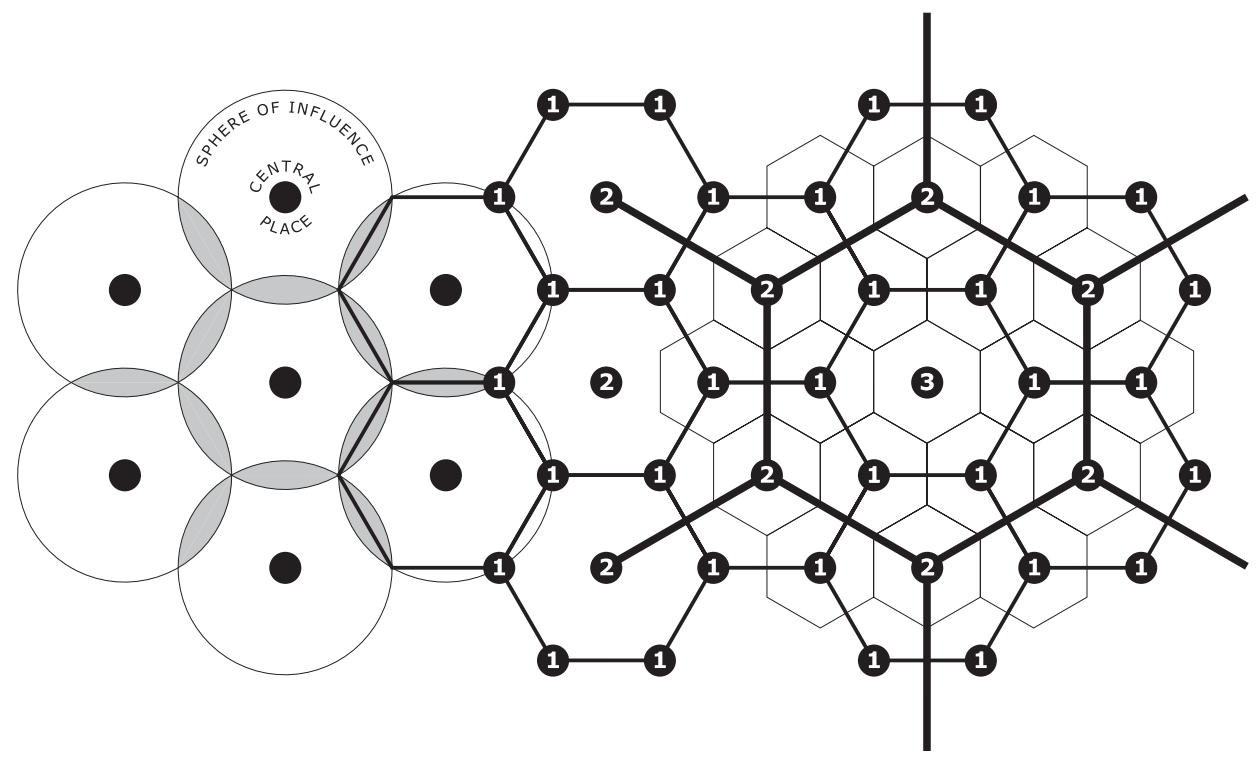

Figure 4

Christaller's Development of First-, Second-, and Third-Order Settlements in a Hexagonal Model That Grew from a Circular Boundary Line Approach.
36 J. Frascara, (1988). “Graphic Design: Fine Art or Social Science?" Design Issues, (Cambridge, MA: The MIT Press), 5:1, 18-29.

37 Although Archer was primarily concerned with general education, this author believes that any discussion about design in general education should align with discussion about design in higher education. B. Archer, "The Three Rs." in B. Archer, K. Baynes, and P. Roberts (eds.), A Framework for Design and Design Education: A Reader Containing Key Papers from the 1970s and 1980s (pp. 8-15). Wellesbourne: The Design and Technology Association.

38 N. Cross, Designerly ways of knowing. (London: Springer-Verlag, 2006). emerge as second-order settlements (e.g., a town) and as more prominent. This pattern gains in complexity with the growth of third-order settlements, which have a wider sphere of influence over first- and second-order places. This influence is shown on the right side of the diagram in a hexagonal pattern that takes in three scales of influence. The diagram shows how one third-order settlement serves 6 second-order settlements and 24 third-order settlements. Overall, 31 settlements are ranked in order of their sphere of influence.

This visual representation, and theoretical base, present a useful opportunity to explore the significant influences on graphic design at macro and micro levels. As an organizational device, this approach is helpful for recognizing disciplinary perspective, but it is worth remembering that boundary lines are a modeling technique, and, like a state or county boundary, they do not exist in the physical sense. Boundary lines are not fixed, but permeable, with significant overlap between approaches that might prompt new spheres of influences to emerge, old ones to dissolve, and new ones to be rediscovered.

The consideration of a hexagonal structure can be useful for discussions about "the basic duality of graphic design" as a "rational and an artistic activity" 36 and reinforces the earlier idea shown by Breen that design (and graphic design) is determined by both the sciences (science and knowledge) and the arts (humanities and expression). Taken further, this author has configured a diagram that makes explicit the ideas of Bruce Archer ${ }^{37}$ and Nigel Cross ${ }^{38}$ — that design is considered a "third culture" in addition to science and the humanities. This possibility has been discussed in detail elsewhere using the idea that design is at the fulcrum of the pendulum that swings between science and the humanities. ${ }^{39}$ This relationship can be seen on the left in Figure 5. 

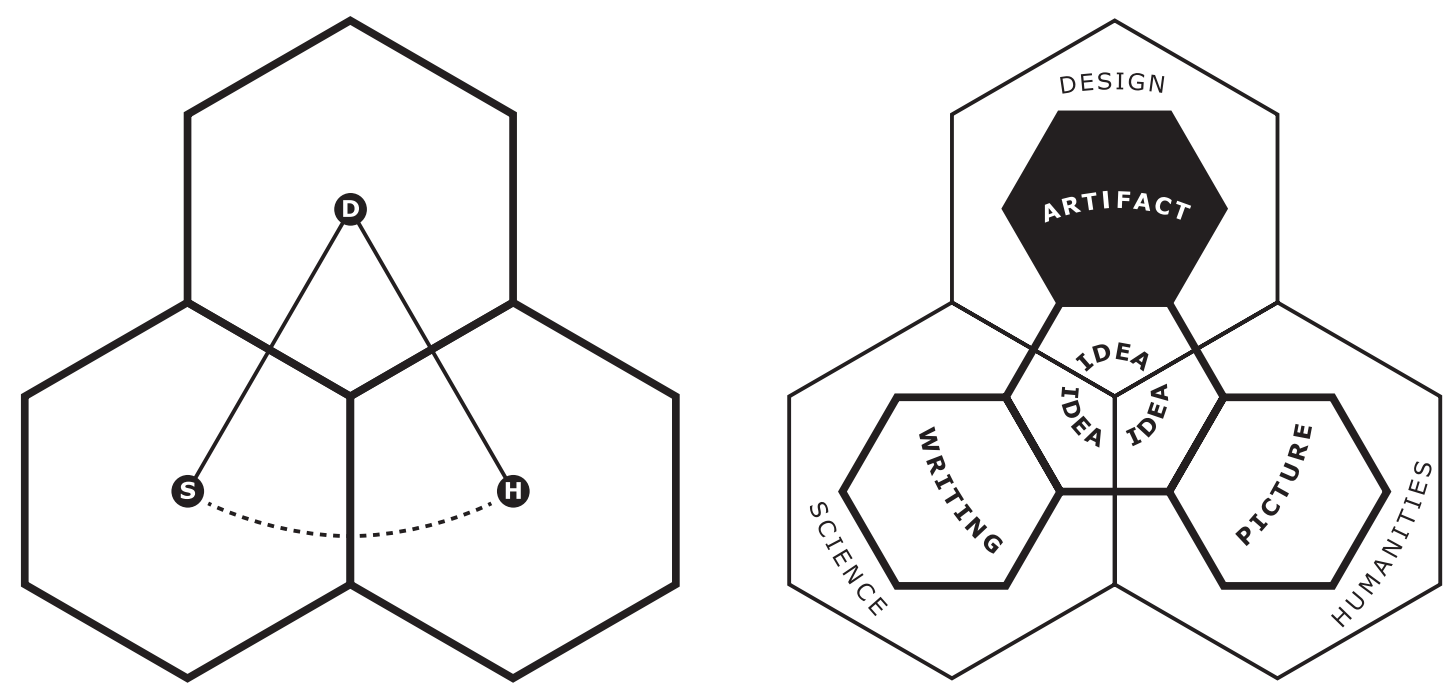

Figure 5

The Macro and Meso Dimensions of Graphic Design.
39 R.G. Harland, (2009). "The Dimensions of Graphic Design: in Theory." Paper presented at the International Association of Societies of Design Research, Design: Rigour and Relevance, Coex, Seoul, Korea, October 18-22, 2009

40 A more comprehensive discussion about duality of terms can be found in $\mathrm{J}$. Elkins, The domain of images. (New York: Cornell University Press, 1999).
As part of the metaphor of a pendulum, an attempt was made to link a number of terms that appear in debates about duality throughout the literature: word/image, verbal/visual, reading (text)/seeing (image), explanation/persuasion, alphabetic/pictorial, objective/subjective. Frasacara's (1988) use of rational/artistic can be added to this. For the purpose of this discussion, the diagram on the right side of Figure 5 emphasizes the basic terms of "writing" and "picture" as appropriate to the "graphic"; these terms are adopted from James Elkins's exploration of the problems with classification in the domain of images. ${ }^{40}$ These are in place of the phrases used earlier: word interpretation and image creation (interpretation and creation having been initially chosen for their respective linguistic and artistic connotations). A more detailed investigation of Elkins's work reveals the use of the "writing" and "picture" classification to be limited in the sense that writing is not exclusively scientific, nor are pictures exclusively the preoccupation of the humanities. He also considers the term "notation" as a third important descriptor before explaining as many as seven categories of images.

The diagram on the right side in Figure 5 conveys the idea that graphic design at a basic level is concerned with ideas about writing systems and pictorial representation, and with their realization in the material form of an artifact. "Artifact" is substituted here for the "media realization" terminology used in Figure 1, and is appropriate because it may refer to either a functional or a decorative object. It is assumed to be a designed object in the physical sense, and the immediate metaphysical terrain that surrounds it might be called the place where design thinking happens.

These new diagrams try to show how we might start to consider the relationships between what might be described as the macro and meso dimensions of graphic design. Trying to look more 
Figure 6

The Complex Spheres of Influence That Contribute to the Micro Dimensions of Graphic Design: Actors, Functions, and Context

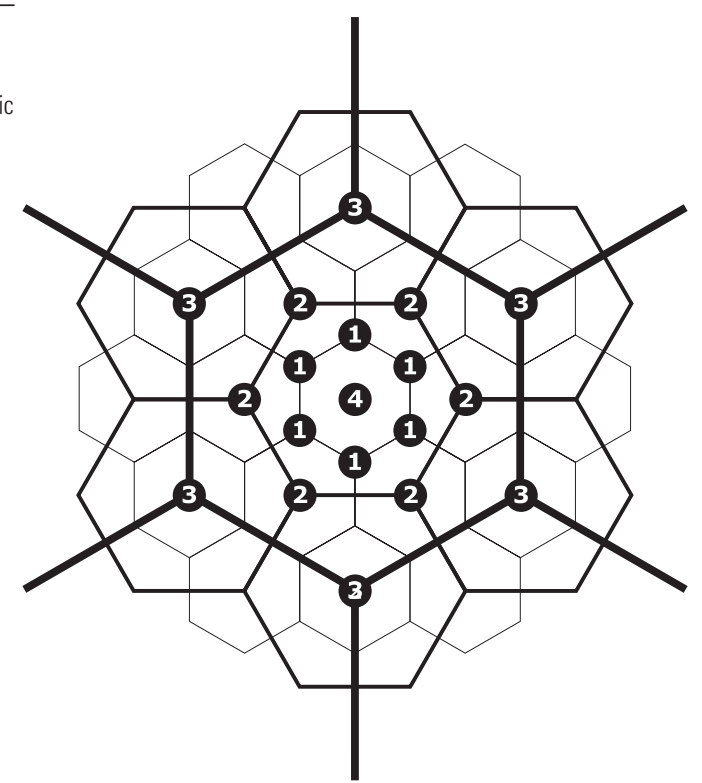

1 Actors

history

theory

criticism

research

education

craft

2 Function

information

persuasion

interpretation

decoration

transformation

relation

3 Context

social

economic

cultural

political

environmental

technological

4 Sphere of influence

all of the above

closely at the micro level requires the complexity of Christaller's first-, second-, and third-order diagrammatic interpretations.

Furthermore, the micro dimensions of graphic design (Figure 6) and their depiction place greater emphasis on the complex relationships that influence the production of the graphic artifact. Micro is used in this context to suggest many influences that are equally balanced, rather than the perceived dominance in the past of craft. (Craft, be it in the form of typography, or printing, has its own macro and micro concerns.) The influences include human and contextual dimensions, some of the latter being sited at the interface between the artifact and its context. The human dimension might include the activities and ideas of practitioners who are concerned with a multiplicity of related activities: history, theory, criticism, research, education, and craft. These activities and ideas may be preoccupations carried out in the plural, or as an autonomous pursuit. The holistic view of the future of graphic design must see the practice of the craftsperson also as that of a historian, theorist, critic, researcher, and educator, as much as that of the historian is seen as theorist, critic, researcher, educator, and crafts person. What is known about history, theory, criticism, research, education, and craft all contribute to the forming of the artifact. Although other occupations can be added, the ones identified are what this author sees as the most important.

The contextual dimension places importance on social, economic, cultural, political, environmental, and technological factors. A multitude of other concerns at a functional level, from both within and outside the graphic design literature, can also be introduced to the model: information, persuasion, interpretation, decoration, transformation, and relation, to name a few. The last of 
these, for example, is frequently the focus of sociological discussion. Individuals will associate and identify with these terms depending on their own disciplinary perspective, randomly aligning them with the human and contextual dimension.

\section{Summary}

This paper has tried to look more closely at the opportunity to depict graphic design in diagrammatic form. Such work appears to have been given little consideration across the near and distant spectrum of literature, despite the perception of diagrams as an integral part of graphic design practice, and the common use of diagrams to explain relationships in other academic subjects. The intention has been educational, as many of the ideas about depiction have been used in a higher education setting, and some of this content has been reported at design research conferences. It would seem that the words of Jorge Frascara in 1988-that graphic design had "developed without much theoretical reflection" —are still true, especially when considering explanations of what the subject is. Historians still report on and feature the objects of graphic design as the primary visual data, whereas criticism and theory have mainly come from a random selection of papers written over the twentieth century, often by those who would not necessarily identify themselves with the term "graphic design."

Figure 7

The Alignment of Artifact with Actors,

Functions, and Contexts

\section{Actors \\ history \\ theory \\ criticism \\ research \\ education \\ craft \\ 2 Function \\ information \\ persuasion \\ interpretation \\ decoration \\ transformation \\ relation \\ 3 Context \\ social \\ economic \\ cultural \\ political \\ environmental \\ technological}

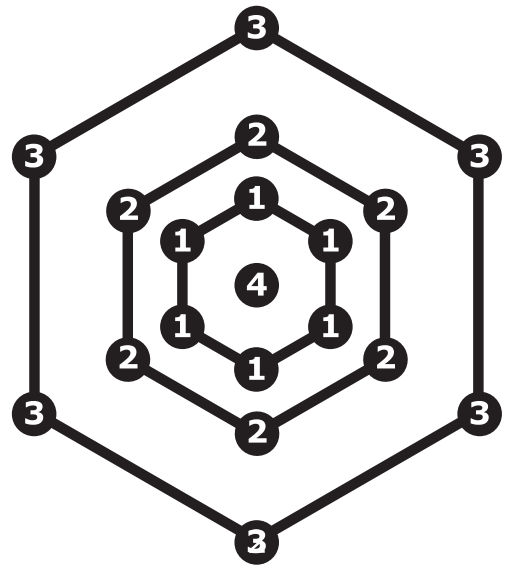

4 Sphere of influence all of the above 
With this situation in mind, this author uses a tool of graphic design — diagrams — as a way to explore and envision graphic design. This project is best described as work in progress, and, as is seen in the diagram in Figure 6, many "territories" remain unexplored. This paper is thus, at best, a summary of where the research currently resides. In fact, the diagram in Figure 6 can be presented in a much cleaner way, simply as three contained hexagons (shown in Figure 7 for those less willing to remove the connecting lines). This diagram is offered to support a discussion about aligning actors, functions, and contexts, in the spirit of what might be called artifact alignment, for which there is much to be written. But removing the lines goes against the spirit of recognition that all of the actors, functions, and contexts are visibly connected to each other through their respective spheres of influence. And they are part of a wider world beyond what is considered design. For some, this reality means placing their primary sphere of influence closer to another complimentary sphere-for example, an interest in social transformation through design education, or the relationships between design, craft, and technology.

Language has been discussed as an important part of this process, with the recognition that the traditional terminology developed out of the establishment of graphic design as a craft for commerce, but it must now be equally thought of as a tool for social, cultural and economic development. Transdisciplinary ways of thinking may well offer the impetus to overcome language barriers and unify a subject that sees history, theory, criticism, research, education, and craft occupying a shared territory. 